\title{
A OPÇÃO PELA ENFERMAGEM: estudo retrospectivo em Sergipe
}

\author{
Normaclei Cisneiros dos Santos Cardoso* \\ Mércia Fernandes Santana Matos** \\ Maria Jésia Vieira***
}

\section{Resumo}

Foi feito um estudo quanti-qualitativo sobre a escolha da profissão de enfermeiro, sua motivação e identificação com a mesma entre graduados e graduandos da Universidade Federal de Sergipe que ingressaram no curso de Enfermagem entre 1992/1 e 1997/1, identificando facilidades ou dificuldades encontradas neste processo. Consta de pesquisa documental nas listas oficiais da Instituição, e entrevistas semi-estruturadas a, pelo menos, $20 \%$ da população. Os resultados revelaram um percentual de apenas $31,5 \%$ de graduados entre os que ingressaram no período, variando os demais entre 5 a 7 anos de permanência no curso. Verificou-se um percentual de $76,92 \%$ de opção preferencial por outros cursos, constatando-se dificuldades de conhecimento ou identificação com a profissão, anteriores ao mesmo, resultantes de estereótipos e tabus culturais.

Descritores: escolha da profissão; motivação; identificação; Enfermagem

\begin{abstract}
A quantitative and qualitative retrospective study was carried out about career choice, motivation and identification in the Nurse profession among graduate professionals and graduate students at UFS (Federal University of Sergipe) who called in from 1992/1 through 1997/1, identifying facilities or difficulties they have found along this process. It consists of documental research in the official lists of the Institution, and of semi-structured interviews with, at least, $20 \%$ of the population. Results showed that only $31.5 \%$ students had graduated over this period, the other ones ranging from 5 to 7 years studying in the program. We found that $76.92 \%$ of them would prefer alternative programs, and difficulties were found either in knowledge or identification with the profession prior its start, which came from stereotypes and cultural taboos.

Descriptors: career choice; motivation; identification; Nursing.

Title: The option for Nursing: a retrospective study in Sergipe.
\end{abstract}

\section{Resumen}

Se hizo este estudio cuantitativo y de calidad entre los graduados y estudiantes de la UFS que habían ingresado entre 1992 y 1997, para saber las razones y motivaciones por las cuales habían elegido el curso de Enfermería e identificar facilidades o dificultades encontradas en ese proceso. Mediante investigación documental en las listas oficiales de la Instituición y de entrevistas semiestructuradas con el $20 \%$ de la población, se obtienen los resultados con un porcentaje del $31,5 \%$ de graduados entre los que ingresaron en el curso. Se verifica un porcentaje del $76,92 \%$ que optó por otros cursos, y se constatan dificultades de conocimiento o identificación con la profesión, anteriores a la elección de la misma y que decurren de estereotipos y tabúes culturales. Descriptores: elección de profesión; motivación; identificación; Enfermería. Título: La opción por la Enfermería: un estudio retrospectivo en Sergipe

\section{Introdução}

Sabe-se que a aprendizagem é parte integrante do desenvolvimento humano com seus fatores cognitivos, que englobam o pensar e o raciocínio, fatores afetivos que englobam o sentir e o estar afetado, e ainda fatores psicomotores que impelem à ação. Esta, provoca mudanças de comportamento ou de conduta na dependência da relação ambiente versus organismo(1-2)

Este desenvolvimento que se inicia com o nascimento indo até a morte é entremeado por um período altamente produtivo onde se quer deixar marcas que registrem a passagem por esta existência através de contribuições sociais e realizações pessoais. É neste âmbito que entra a profissionalização como um meio de se conseguir estas marcas.

Este processo é transpassado por situações desafiantes que muitas vezes geram desequilíbrios internos que transcendem o agir externo. Na Teoria Cognitiva de Piaget, a sucessão ontogenética consiste em conseguir uma coordenação equilibrada dos vários estados de desequilíbrio à procura de reequilíbrio nas relações entre o sujeito e o ambiente $e^{(1-3)}$.

Neste processo, trazendo para o tema específico deste estudo, ao se atingir certa maturação sente-se a aptidão para desempenhar uma dada profissão e para tal o indivíduo se propõe ao enfrentamento do vestibular vislumbrando uma gama de possibilidades, com predominância para os cursos de maior status social. As perspectivas econômicas de um país de desigualdades e de preconceitos, podem levar à procura de uma ascendência social não condizente com os anseios de vida profissional.

As diferenças de capacidades, interesses e personalidades, podem ser, entretanto, responsáveis pelo aumento crescente na procura por cursos diversos, e entre eles o de Enfermagem, apesar da prevalência de outros cursos ditos de maior status e de melhor remuneração.

Assim sendo, este trabalho pretendeu realizar um estudo retrospectivo sobre as opções pela Enfermagem com seus anseios, perspectivas e motivações, e as possíveis mudanças na valoração da profissão. Pretendeu, ainda, conhecer o perfil desta população, identificando as facilidades e/ou dificuldades encontradas no transcorrer da escolha à identificação com a mesma entre ex-alunos graduados e graduandos que ingressaram no curso no período que vai de 1992/1 a 1997/1 na UFS.

\section{Revisão de literatura}

Para se perceber as razões que levam à opção pela Enfermagem como profissão, precisamos conhecê-la na sua essência, entendê-la, senti-la e acima de tudo saber quais as ações por ela desenvolvidas. Pode-se conceituá-la como uma

\footnotetext{
* Enfermeira do Hospital Governador João Alves Filho, professora substituta do departamento de Enfermagem e Nutrição da Universidade Federal de Sergipe.

** Enfermeira do Programa de Saúde da Família na Prefeitura de Lagarto - Sergipe.

*** Enfermeira. Professora assistente doutora do Departamento de Enfermagem e Nutrição da Universidade Federal de Sergipe.

E-mail do autor: mjvieira@infonet.com.br
} 
"profissão de caráter essencialmente social que significa servir à humanidade, atendendo às necessidades do indivíduo e da sociedade"(4:88). "A pessoa humana é o foco de atenção da enfermagem"(5:30), cuja assistência prestada "é uma forma de ajudar o cliente a vencer dificuldades ligadas às necessidades fundamentais"(5:30)

Não se pode falar em enfermagem sem citar Florence Nightingale e da influência exercida por esta sobre a opinião pública para que ocorresse a elevação do status social, pelo fato de ser ela membro da alta burguesia e ser tratada como heroína nacional. A organização e a administração por ela desenvolvidas, juntamente com a disciplina e rigor moral, enfatizavam, assim, as aptidões físicas e intelectuais, em busca de uma Enfermagem sem o estigma da imoralidade, do baixo padrão técnico, de um trabalho manual doméstico sem nenhum conhecimento científico. A enfermagem deveria ser encarada como profissão e vocação(6)

"A enfermagem no Brasil iniciou tendo o corpo do indivíduo como objeto, porém visando atingir o espírito"(5:31). A atividade era de cunho religioso caritativo e a assistência que era destinada aos doentes e à comunidade incluindo pobres, abandonados, desprotegidos e todos que assim precisassem de assistência, tendo religiosos, monges, escravos, pessoas de posse à frente desta assistência.

Entretanto, no que se refere ao poder da Igreja Católica, tal como em outros países, enquanto esta assistência lhe servia para atrair adeptos, e manter os interesses políticos na era colonial, ela a assumiu como sua obra. No entanto, quando essa assistência não the servia mais como elo de submissão e obediência dos seus assistidos, a tática da Igreja Católica foi a de não mais privilegiar esta assistência, deixando-a entregue em outras mãos, resultando, na vinculação da figura da mulher às ações de enfermagem ${ }^{(5)}$.

Assim, verifica-se mais uma vez que os papéis são culturalmente definidos e aprendidos, e que a aprendizagem depende do contexto sócio-econômico da época em questão(5).

Refletindo-se sobre os contextos culturais de diversas épocas, a ascensão social que a profissão adquiriu, levou-a a ser procurada por indivíduos de classe média em virtude de uma estrutura social modificada, onde as classes cada vez mais se distanciam, acentuando suas diferenças. Neste sentido, o surgimento do setor terciário a partir do incremento da industrialização, ocasionou a vinculação da Enfermagem a este setor. Assim, "a participação crescente da mulher na força de trabalho parece constituir uma característica das sociedades mais urbanizadas e mais industrializadas"(6:83).

Como conseqüência da divisão de classes, surge a divisão do trabalho como também a especialização da profissão(4). Este processo atinge em cheio a Enfermagem já que seu objeto de trabalho se divide entre o trabalho manual, que se destina ao cuidado efetivo do indivíduo, e o trabalho intelectual destinado ao planejamento e fiscalização dos serviços. "Esta separação entre quem dirige e quem executa faz com que o trabalhador se distancie do produto de seu trabalho, e transforma as relações dos indivíduos, hierarquizando-as"(4:33).

Poder-se-ia, ainda, encontrar como um efeito desta divisão do trabalho a má impressão que a sociedade tem a respeito desta profissão, já que de um lado encontra-se auxiliares e técnicos de enfermagem realizando suas atividades de forma automática e com menor grau de conhecimento científico, e do outro lado enfermeiros que se denominam por "enfermeiros-chefe" distanciados da assistência direta. Estes conseguem a proeza de continuar separando a prática da teoria, contrapondo-se desta forma, aos princípios preconizados no ensino da Enfermagem, que procuram integrar os dois aspectos, de forma que um (prática) não exista sem o outro (teoria) $)^{(5,7)}$

Não obstante esta divisão, e até vinculada a ela, no decorrer da própria história da enfermagem há uma ampliação das suas atividades, no sentido de que a assistência se torne mais eficiente e eficaz, através de ações dependentes, interdependentes e independentes ${ }^{(5,7)}$.

É interessante lembrar, também, a separação que houve, no século XIX no Brasil, entre o cuidar e a cura, pois o cuidar, antes revestido de simplicidade, foi transformado a partir da tecnologia sanitária emergente, dividindo-se em curar masculino e o cuidar feminino ${ }^{(9)}$.

À enfermagem cabia o cuidar, “... que requer devotamento, espírito de renúncia, abnegação, aceitação e respeito aos outros, principalmente, aos superiores hierárquicos" (5:35), ficando clara a herança de preconceitos e discriminações que cercam a profissão. À medicina cabia a cura, o tratamento do indivíduo como um todo, e neste, a enfermagem atuava apenas como coadjuvante.

Neste contexto, numa tentativa de equiparar-se aos traços masculinos, "objetividade e (...) neutralidade" o perfil da enfermagem no início da sua profissionalização era o da "estabilidade emocional, distinção moral, apresentação respeitosa", "distanciamento, dinamismo, direcionando o ensino e a prática da época" . A profissional teria que ser "destituída da mulher", teria que romper com algumas características intrínsecas dos seres humanos como os sentimentos de amizade, de troca e de interação. Ser competente e respeitável era sinônimo de autoritarismo e dureza ${ }^{(5: 38-40)}$. Entretanto, diferente do público em geral, na construção da imagem que os enfermeiros se atribuem há a motivação como fator preponderante na escolha e no desempenho da profissão.

Os motivos sociais que intervém nesta construção, têm suas origens no "desenvolvimento social da criança"(10:146), entendidos estes como instintos sociais básicos de sociabilidade, simpatia, amor, ciúme e imitação.

Mais tarde, as canalizações são ampliadas, de modo que a criança escolar passa a ser também influenciada pelos valores dos colegas, o estudante universitário pelas expectativas de seus confrades acadêmicos, e o adulto por sua filiação numa determinada classe social, grupo étnico, partido político, organização religiosa, associação profissional ou comunidade

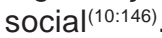

Estes motivos sociais que contribuem para a valoração acerca de si mesmo, e ainda, o papel a ser desenvolvido no grupo, fazem parte de um processo de socialização, onde "o indivíduo busca na sua escolha profissional uma forma de se sentir útil às outras pessoas bem como de saber o que esperar delas"(7:29) entendendo-se a opção profissional "como a necessidade de exercer uma função, de ser útil, de encontrar seu espaço, levando em conta as características do seu tempo"(7:10)

A respeito da formação da imagem cultural da profissão, da percepção desta imagem e das motivações para a escolha profissional, entende-se que a imagem da profissão compõese de traços culturais permanentes e transitórios, materiais e não materiais, explicitados ou simbolizados, valorados como positivos ou negativos, propiciando um movimento de aproximação ou afastamento. Esta imagem é percebida pelo sujeito, que poderá escolher a profissão pela sua identificação com esta imagem, pela valoração dos traços positivos ou pelo desejo de superação de traços negativos ${ }^{(7)}$.

Assim, buscou-se conhecer este processo de escolha e identificação no grupo estudado, com suas facilidades e dificuldades.

\section{O caminho metodológico}

O estudo identifica-se como uma pesquisa quanti qualitativa $^{(11)}$, partindo-se inicialmente da análise documental de listas oficiais da UFS (tabelas 1 e 2) optando-se pela abordagem representacional para os dados qualitativos, pelo 
fato de esta dar apoio ao propósito descritivo, com condições de coleta de informações as mais diversas possíveis sobre determinado grupo de pessoas, instituição ou fenômeno social. As representações sociais buscam traduzir como as pessoas representam fatos, objetos e situações, fazendo um elo entre a realidade dos fatos sociais, com suas mudanças culturais e contextuais, e a realidade individual com suas diferentes formas de interpretação desta realidade, que nortearam a conduta comportamental e expressiva destes na sociedade em que vivem. Assim, cada indivíduo quando emite sua representação, reflete também a representação da cultura e da sociedade da qual faz parte (7)

A Universidade Federal de Sergipe foi tomada como campo de pesquisa com sua população de egressos e estudantes do Curso de Enfermagem, bem como estudantes de enfermagem que abandonaram o curso os quais foram sujeitos de uma outra pesquisa. O critério de seleção da amostra foi não-probabilística, intencional e estratificada, incluindo graduados e graduandos de todos os períodos letivos do tempo em estudo (63 sujeitos). A seleção foi feita pelas listas dos que ingressaram na UFS entre 1992/1 a 1997/1.

O período escolhido pretendeu cobrir, em dois subprojetos, as mudanças culturais ocorridas ao longo de 10 anos, a partir dos alunos que iniciaram seu curso em 1992/1, a 1997/1, que já concluíram o curso, ou teoricamente teriam tempo suficiente para isto, e os formandos do período de realização da pesquisa, acrescidos, no segundo subprojeto dos alunos em curso, até 2002/1.

Das listas de graduados foram escolhidos os primeiros componentes da amostra pelo critério de facilidade de acesso. Estes, por sua vez, fizeram a indicação de outros possíveis entrevistados, e a partir destes formou-se uma rede de informantes até perfazer, no mínimo, $20 \%$ da população, chegando a $40 \%$ no caso dos graduandos. Através destas listas foi estabelecido o percentual de graduados em relação ao número de ingressos.

Foi usado ainda um questionário à amostra, abrangendo as questões relativas à opção, identificação, facilidades e dificuldades, após os mesmos terem assinado o termo de consentimento livre e esclarecido, mediante explicações quanto aos objetivos, procedimentos, seus direitos de serem esclarecidos quando necessário, privacidade e liberdade para retirada do consentimento. O projeto do estudo foi aprovado pelo Comitê de ética em pesquisa do Hospital Universitário da UFS em 06/12/2001.

A análise foi quantitativa com tratamento estatístico para as questões fechadas, enquanto que para as questões abertas foi feita uma análise de conteúdo ${ }^{(8)}$. Nesta, foi feita uma préanálise de cada entrevista, identificando as categorias que emergem das falas, e em seguida o agrupamento destas em categorias maiores, em correspondência com as questões da pesquisa.

\section{Resultados e discussão}

Pelo levantamento das listas de graduados que ingressaram entre 1992/1 e 1997/1 teoricamente dever-se-ia ter, a cada quatro anos e meio, vinte alunos formados por período, totalizando, portanto, duzentos, incluindo-se os formandos do semestre em curso. Os dados mostram uma realidade diferente desta, onde, no total das dez turmas, apenas sessenta e três enfermeiros se graduaram $(31,5 \%$ em relação aos que ingressaram).

Analisando o tempo de duração do curso entre a população estudada, visualizou-se a situação mostrada na Tabela 1, surgindo um novo questionamento, no que refere a saber se todos os aprovados foram matriculados no curso. Buscou-se, então as listas de matriculados por período, cujo confronto com a lista dos aprovados no vestibular, deu origem à Tabela 2.
TABELA 1 -TEMPO DE DURAÇÃO DO CURSO NA POPULAÇÃO ESTUDADA. ARACAJU, 2002.

\begin{tabular}{c|l|c}
\hline \multirow{2}{*}{$\begin{array}{c}\text { Duração } \\
\text { (em anos) }\end{array}$} & \multicolumn{2}{|c}{ Total de Alunos } \\
\cline { 2 - 3 } & $\mathrm{N}^{\circ}$ & $\%$ \\
\hline 9,0 & 01 & 1,59 \\
8,0 & 01 & 1,59 \\
7,5 & 01 & 1,59 \\
7,0 & 06 & 9,52 \\
6,5 & 11 & 17,46 \\
6,0 & 11 & 17,46 \\
5,5 & 10 & 15,87 \\
5,0 & 14 & 22,22 \\
4,5 & 07 & 11,11 \\
$4,0^{\star}$ & 01 & 1,59 \\
\hline TOTAL & $\mathbf{6 3}$ & $\mathbf{1 0 0}$ \\
\hline
\end{tabular}

Fonte: DAA (Departamento de Administração Acadêmica da UFS)

* realizado um outro vestibular, aproveitando matérias cursadas e reduzindo assim a duração do curso.

TABELA 2-APROVADOS NO VESTIBULAR QUE DERAM CONTINUIDADE AO CURSO DE ENFERMAGEM. ARACAJU, 2002.

\begin{tabular}{c|c|c|c}
\hline \multirow{2}{*}{$\begin{array}{c}\text { Ano de } \\
\text { ingresso }\end{array}$} & \multirow{2}{*}{$\begin{array}{c}\text { Aprovados } \\
\text { no vestibular }\end{array}$} & \multicolumn{2}{|c}{$\begin{array}{c}\text { Graduados ou em } \\
\text { processo de } \\
\text { graduação }\end{array}$} \\
\cline { 3 - 4 } & & Número & Percentual \\
\hline 1992 & 40 & 25 & 62,5 \\
1993 & 40 & 18 & 45,0 \\
1994 & 40 & 30 & 75,0 \\
1995 & 40 & 32 & 80,0 \\
1996 & 40 & 33 & 82,5 \\
\hline Total & $\mathbf{2 0 0}$ & $\mathbf{1 3 8}$ & $\mathbf{6 9 , 0}$ \\
\hline
\end{tabular}

Fonte: DAA (Departamento de Administração Acadêmica da UFS)

A tabela 1 chama a atenção para o fato de que somente $11,11 \%$ da população conclui o curso dentro do tempo previsto, chegando a ter $1,59 \%$ da amostra concluindo o curso no dobro do tempo.

Percebeu-se a partir dos dados da tabela 2 que 31\% dos aprovados no curso de Enfermagem no período estudado não deram continuidade ao curso escolhido no vestibular. Entretanto, pode-se verificar um aumento da taxa de permanência nos dois últimos anos, com respectivamente 80 e $82,5 \%$.

Ao se questionar a quantidade de vezes que os mesmos prestaram vestibular, $53,75 \%$ o fez duas vezes, enquanto $34,62 \%$ o fez por três ou mais vezes, e apenas 11,63 o fez por uma vez. Quanto aos motivos que os levaram à escolha pelo curso, em $42,31 \%$ dos casos, deveu-se a uma forma de entrar na Universidade; 3,85\%, a experiências de doença; 7,69\% à boa oferta de emprego na profissão; $11,54 \%$ a experiências de trabalho em hospital ou após curso de auxiliar de Enfermagem; $15,38 \%$ ao contato com profissionais da área, dando oportunidade de tomar conhecimento da profissão; 6,69\% à pressão de familiares e à curiosidade, e apenas $11,54 \%$ se reportam à afinidade e/ou vocação. 
Ao se questionar quando teria ocorrido o processo de identificação com a profissão, foram encontrados os resultados a seguir:

\section{TABELA 3-PERÍODO E/OU OPORTUNIDADES DE IDENTIFICAÇÃO} COM APROFISSÃO. ARACAJU, 2002.

\begin{tabular}{l|c}
\hline \multicolumn{1}{c|}{ Identificação com a profissão } & $\%$ \\
\hline Início do curso através da disciplina & 7,69 \\
Fundamentos de Enfermagem & \\
Início do curso durante a Semana de & 3,85 \\
Enfermagem & 46,15 \\
Início das disciplinas profissionalizantes & 19,23 \\
Já tinham experiência na área & 7,69 \\
Só quando começou a exercer a profissão & 11,54 \\
No último ano do curso & 3,85 \\
Não se identificou ainda & \\
\hline
\end{tabular}

O início das as disciplinas profissionalizantes aparecem como o espaço privilegiado de identificação. Estes dados reforçam o pressuposto de que uma das dificuldades de escolha e identificação com a profissão diz respeito à falta de conhecimento sobre ela.

Quando se questionou sobre as facilidades e/ou dificuldades encontradas no processo de identificação com a profissão, 26,92\% referiu como facilidades o conhecimento prévio e/ou experiências de trabalho na área. Os outros 73,08\% fizeram referência apenas às dificuldades e, entre elas, o desconhecimento da profissão, a demora para iniciar as aulas práticas, o preconceito da sociedade em relação à profissão.

A impressão, antes da entrada no curso, também foi questionada e pode-se selecionar algumas conotações positivas nas falas dos respondentes, tais como: boa impressão sobre o curso, grandes oportunidades de trabalho. Conotações negativas também aparecem, tais como: desvalorização do curso pela sociedade, confundindo as atribuições das diversas categorias da Enfermagem, profissão dependente das atividades do médico/sem autonomia.

Essas impressões sofreram mudanças positivas e/ou negativas no decorrer do curso. Como positivas destacaramse: valorização aumentada por amigos e familiares, conhecimento sobre as amplas funções e sobre a autonomia do enfermeiro, grande possibilidade de realização profissional, tratamento do doente e não da doença com variedades de atuação. Como negativas foram citadas: potencial pouco explorado pela educação continuada, afastamento das práticas diárias do cuidado direto, falta de posicionamento político, e liderança.

Com relação às perspectivas de realização profissional, os respondentes manifestaram sua perspectiva de: "fazer a diferença na vida do cliente"; poder conciliar a atividade hospitalar por afinidade, com a atividade em Saúde Pública por proporcionar melhores salários; fazer especialização para uma melhor colocação profissional; tentar mudar a imagem da Enfermagem e contribuir para sua valorização.

Discutindo-se estes dados para responder aos questionamentos iniciais pode-se destacar algumas categorias temáticas da análise de conteúdo:

\subsection{Caminhar até o vestibular}

Sabe-se que na sociedade, cada vez mais precocemente os pais colocam seus filhos para estudar, atividade esta que irá desenvolver por grande parte da sua existência. Ingressar no $3^{\circ}$ grau passa a ser um objetivo ansiosamente perseguido. Porém persegue-se também o status social, e por isso durante toda preparação pré-universitária ouve-se falar incessantemente em cursos de maior valorização social como deixa claro o depoimento de um dos respondentes: "os professores dos cursinhos só falam em medicina, direito, odontologia, em momento algum eles falam em outra profissão, ou se quer sabem o que estas fazem".

Como reflexo do tipo de preparação, com ênfase no status social, verificou-se na população estudada uma multiplicidade de vezes que se prestou vestibular, prioritariamente para medicina (50\%) e $26,92 \%$ para outros cursos e, mais tarde, para enfermagem, denotando a hegemonia cultural dos outros cursos. Dados encontrados por outros autores refletem, também a mesma realidade ${ }^{(12) .}$

É interessante notar que apenas $23,08 \%$ dos questionados tiveram enfermagem sempre como opção preferencial, seja através de um único vestibular ou de vários. Isto pode ser conseqüência da falta de informação sobre a profissão e suas competências, já que estas só são acessíveis após o ingresso ao curso ou estão restritas aos trabalhadores da área.

Como divulgadora das atribuições profissionais a mídia tem deturpado a imagem e contribuído negativamente ao traçar o perfil do enfermeiro. A imprensa "associa a profissão à devoção religiosa, à 'doação' e à figura do profissional que cumpre ordens médicas, ou ainda imagens estereotipadas que denigrem o enfermeiro" ${ }^{(13: 28)}$, refletindo o descompasso entre a imagem que a impressa e o público fazem da enfermagem, e a que realmente esta tem sobre si.

\subsection{Motivação para a Enfermagem}

Ao se observar os motivos do ingresso no curso de Enfermagem conseguiu-se evidenciar alguns caracteres importantes da população estudada. Sabendo-se que 42,31\% escolheram o curso apenas por ser uma forma de entrar na universidade, e que $76,92 \%$ não tiveram enfermagem como opção preferencial, conclui-se que este percentual iniciou o curso sem se identificar com ele. Merece destaque o percentual de $26,92 \%$ de escolha devido ao primeiro contato com a profissão, quer por trabalho em área hospitalar ou curso de auxiliar, quer por contato com profissionais que atuam na área, reforçando a idéia de que o conhecimento prévio sobre a profissão que se pretende exercer, proporciona uma maior segurança na escolha. $\mathrm{E}$ ainda, embora com menor freqüência, pode-se perceber, também como motivos a boa oferta de empregos $(7,69 \%)$ e afinidade e/ou vocação (11,54\%).

\subsection{A graduação em Enfermagem}

Os dados apresentados na tabela 2 denotam a falta de adesão ao curso, vez que se tem de um lado um alto índice de desistência (31\%), e de outro um grupo de indivíduos que levaram o curso até o fim sem muita pressa para terminá-lo. É claro que das falas dos respondentes pode-se detectar alguns motivos pela demora, como a existência de uma disciplina que se constituía em entrave, motivado por tratamento diferenciado de um docente em relação aos alunos do curso, depreciandoo e dificultando o desempenho dos mesmos. Um outro motivo relatado diz respeito à necessidade de trabalhar concomitantemente ao desenrolar do curso, ou até mesmo diversos trancamentos por motivos de doença, trabalho, filhos. No entanto a característica principal desta demora deveu-se ao fato de inúmeras tentativas de vestibulares para outros cursos, não aderindo à seqüência prevista.

\subsection{Processo de identificação profissional}

Referente à identificação profissional a tabela 3 revela algumas singularidades como a importância das disciplinas profissionalizantes $(46,15 \%)$ como o primeiro contato com o "fazer enfermagem", já que o "ser enfermeiro" começa a se delinear com a disciplina Fundamentos de Enfermagem; 
seguido de 19,23\% relativos a um contato prévio com a profissão, quer através de curso auxiliar e/ou trabalho no ambiente hospitalar quer pelo contato com profissionais que atuam na área. Novamente fica claro que quando o aluno toma conhecimento pleno sobre o curso que escolheu, poderá se identificar mais facilmente. Foi encontrado $23,08 \%$ de identificação posterior ao início do curso, e/ou no exercício da profissão, acrescidos dos que afirmam categoricamente não se terem identificado.

No que se refere às facilidades, encontra-se $26,92 \%$ desta população referindo o conhecimento prévio e/ou experiências na área, reforçando ainda mais a necessidade de maiores informações sobre a Enfermagem e suas atribuições. Os 73,08\% referem dificuldades como o desconhecimento da profissão, seja pela falta de informações ou pela demora no início das práticas, e ainda o preconceito da sociedade, inclusive de alguns professores, situação esta, também referida na literatura(14).

\subsection{A imagem da profissão}

Abordando-se as impressões e/ou possíveis mudanças ocorridas na imagem da profissão antes ou durante o curso apenas uma minoria se reporta a uma boa impressão antes, incluindo grandes oportunidades de trabalho, e entre estes estão os que já possuíam conhecimento prévio sobre a profissão. O restante refere-se à desvalorização da profissão seja pela não diferenciação entre os afazeres do técnico, auxiliar e enfermeiro, seja pela atribuição de um caráter de dispensabilidade dos afazeres do enfermeiro, ou pelo estereótipo de dependência das prescrições médicas.

Tais estereótipos foram evidenciados também por outros autores ${ }^{(4-6,9)}$ quando retomam a historicidade que relaciona o cuidar com o fazer feminino dependente do curar masculino. Referem, entretanto, a participação feminina na força de trabalho, já representando um ganho social e trabalhista, sendo este, desvinculado da religião. Fazem, ainda, alusão ao conhecimento científico como uma característica incorporada mais recentemente, pois no início das práticas, estas se identificavam muito mais como técnicas, ligadas às habilidades manuais, sendo estas, hoje, a base das atribuições do técnico e do auxiliar de enfermagem.

Tais impressões sofrem mudanças quando se dá prosseguimento ao curso, conforme as falas dos respondentes. É verdade que nem sempre elas recebem uma conotação positiva, como o fato do elevado número de atribuições do enfermeiro, levando-o a uma não participação efetiva no cuidado direto, bem como a falta de posição política e de liderança.

Estes aspectos negativos vão de encontro às características básicas da Enfermagem, pois o enfermeiro deve produzir e propagar o conhecimento, cabendo-lhe administrar, realizar e fiscalizar a assistência, tendo total responsabilidade sobre a tomada de decisão e execução da mesma, sem deixar de lado sentimentos de troca, interação e amizade ${ }^{(5,7)}$. A percepção destes aspectos é mais evidente no grupo amostral que percebe a valorização a partir do contato com familiares e amigos enfermeiros, quando também passam a conhecer melhor as atribuições do profissional, com verdadeira autonomia, ao tratar o doente e não a doença.

Este grupo vê a possibilidade de realização profissional com um grande potencial a ser explorado, principalmente pela educação continuada, sobre a qual demonstram interesse quanto à oferta e realização. Esta situação configura a formação da imagem profissional, formada por traços que quando valorizados propiciam uma aproximação e identificação do indivíduo com a mesma, passando a incorporá-la (7).

Entre seus fatores cognitivos, afetivos e psicomotores, destacam-se a visão prévia da profissão, seja por experiência de vivência, entrando em contato assim com informações precisas e coerentes a respeito das atividades exercidas; seja por informações obtidas através da literatura, filme, teatros, histórias, ou ainda como clientes num tratamento de saúde ${ }^{(7)}$. Sobre isso, um estudo realizado em Sergipe ${ }^{(15)}$ revelou que na prática um dos motivos da evasão no curso de Enfermagem na Universidade Federal de Sergipe referente ao período estudado de 1991/2 a 1996/1, deveu-se a falta de informações pelos alunos ao afirmarem que, "no momento em que fizeram a opção no vestibular nenhum dos alunos tinha conhecimento sobre a Enfermagem como profissão, e muito menos sobre o curso"(15:32).

\subsection{Ser Enfermeiro}

Ao se questionar a respeito das perspectivas de realização profissional percebeu-se uma discreta insegurança quanto ao campo de trabalho, porém suplantado pelo desejo de fazer a diferença nesta categoria, através da obtenção de maiores conhecimentos, contribuindo desta forma para a valorização da profissão. No âmbito desta percebeu-se referência ao surgimento do Programa de Saúde da Família como sendo um passo rumo a um maior reconhecimento sobre as verdadeiras capacidades e potencialidades da Enfermagem, bem como propiciando melhores salários.

A literatura refere que "o modo como as pessoas diferem em termos e aptidões, capacidades, interesses, traços de personalidade, valores, necessidades, ajustamento e motivações são aspectos que apresentam considerável importância..."(14:33), quando se desempenha uma profissão. Mas, também se deve atentar para o fato de que para se exercer bem uma profissão, é preciso mais que uma identificação. É necessário ter condições de viver bem, de atender ao menos alguns itens referentes a bem estar.

\subsection{Continuar sendo Enfermeiro}

Questionados sobre se recomendariam a outrem o curso, obteve-se respostas, $80 \%$ positivas, como a possibilidade de campo de trabalho com remuneração razoável, alguns aconselhamentos a respeito de uma reflexão sobre os fazeres da Enfermagem, devendo, estes, serem revestidos de dedicação, solidariedade e gosto pelo estudo...; assumir sua decisão, não deixando que a família tome a iniciativa...; relacionar vocação, afinidade e aptidão com retorno financeiro...; conhecer o verdadeiro papel do profissional atuante..., amar verdadeiramente o que se faz...; ter certeza da escolha para não se tornar um profissional frustrado... Encontrou-se também $20 \%$ de respostas negativas como o fato de ter de "trabalhar muito para conseguir sobreviver". Pode-se perceber o vislumbrar da conjugação da realidade do trabalho com a importância atribuída à profissão, acrescidas ao fato de que aconselhar, expondo os prós e os contras, passa a ser um ato de cidadania para evitar que outros incorram em erros.

Pode-se identificar, pelas falas, que a escolha e identificação já não se fazem mais somente por razões caritativas como afirmam alguns autores ao dizerem que "a Enfermagem é percebida como uma profissão de amor ao próximo, uma forma de chegar perto de Deus, mas também como desafio e luta por uma profissão melhor"(16: 307). A profissão tem sido escolhida com vistas a uma realização profissional e financeira, expressando-se através dos sistemas adaptativo, associativo e ideológico coincidindo com seu mundo e incidindo sobre ele; convivendo, expressando-se, tendo ainda como enfoques a sobrevivência e a facilitação do $\operatorname{viver}^{(7)}$.

\section{Conclusões}

A partir do exposto, apreende-se que na escolha da profissão, além da informação prévia a respeito desta, é preciso que exista coerência entre as necessidades sociais, tendências pessoais, oportunidades concretas oferecidas, e ainda, o momento pessoal do indivíduo, sua maturidade mental e sua inserção na sociedade.

O estudo revelou a existência de dificuldades neste 
sentido, pela falta de informação, a pressão social da família, das escolas de $2^{\circ}$ grau, da imprensa, que incentivam a escolha por profissões tidas como de maior "status" social, sem valorizar a vocação, tendências pessoais e identificação do indivíduo, e tão pouco, a possível auto-realização, implicando, isto na necessidade de orientação dos jovens que estão escolhendo a profissão.

Constatou-se, em vista disto, baixo percentual de escolha preferencial por enfermagem, revelando os respondentes que o conhecimento e a identificação só ocorreram, na maioria das vezes durante o curso. As disciplinas profissionalizantes exerceram grande contribuição neste sentido, mas há o apelo dos mesmos para que estas se iniciem mais precocemente. Constatou-se, ainda, grande número de evasão escolar e/ou de retenção no curso por mais tempo que o necessário.

Entre os que se identificaram com a profissão, suas motivações se caracterizaram, principalmente, pela possibilidade de um trabalho onde se possa exercer uma ação de ajuda, o cuidar, com a perspectiva de realização profissional, e de provisão de suas necessidades financeiras. Indicam os atuais programas de Saúde Pública como uma boa perspectiva financeira para a profissão, embora alguns tentem compatibilizar o trabalho nesta com outro vínculo funcional como a assistência hospitalar, com a qual se identificam.

Diferentemente da conotação histórico social tradicional, a profissão não é mais vista pelos informantes como caridade e dependência, mas como uma área de saber próprio, autônoma, onde se busca crescer pela educação continuada e/ou cursos de pós graduação.

\section{Referências}

1. Campos DMS. Psicologia da aprendizagem. $27^{\text {a }}$ ed. Petrópolis (RJ): Vozes; 1998. 304 p.

2. Mussen $\mathrm{PH}$, Conger JJ, Kagan J. Desenvolvimento e personalidade da criança. $8^{a}$ ed. São Paulo: Harbra; 1995. 561 p.

3. Falcão GM. Psicologia da aprendizagem. $5^{\text {a }}$ ed. São Paulo: Ática; 1989. $237 \mathrm{p}$.
4. Germano RM. Educação e ideologia da enfermagem no Brasil. São Paulo: Cortez; 1983. 118 p.

5. Passos ES. De anjos a mulheres: ideologia e valores na formação de enfermeiros. Salvador (BA): EDUFABA/EGBA; 1996. 209 p.

6. Alcântara G. Enfermagem moderna como categoria profissional: obstáculos à sua expansão na sociedade brasileira [tese de cátedra]. Ribeirão Preto (SP): Escola de Enfermagem de Ribeirão Preto, Universidade de São Paulo; 1963. $117 \mathrm{f}$

7. Vieira MJ. Imagem e motivação na escolha da profissão [tese de Doutorado]. Ribeirão Preto (SP): Escola de Enfermagem de Ribeirão Preto, Universidade de São Paulo; 1998. 172 f.

8. Bardin L. Análise de conteúdo. Lisboa: Edições 70; 1977. 227 p.

9. Rossi MJS. O curar e o cuidar: a história de uma relação. Revista Brasileira de Enfermagem, Brasília (DF) 1991 jan/mar;44(1):16-21.

10. Murray El. Motivação e emoção. $5^{a}$ ed. Rio de Janeiro: Guanabara Koogan; 1986. $177 \mathrm{p}$

11. Polit DF, Hungler BP. Fundamentos de pesquisa em enfermagem. $3^{a}$ ed. Porto Alegre (RS): Artes Médicas; 1995. 391 p.

12. Spíndola T, Moreira A. O aluno e a enfermagem: por que esta opção profissional? Escola Anna Nery: Revista de Enfermagem, Rio de Janeiro 1999 dez;3(3):25-37.

13. Sanna MC, Secaf V. A imagem da enfermeira e da profissão na imprensa escrita. Revista de Enfermagem da UERJ, Rio de Janeiro 1996 dez;4(2):170-82.

14. Takahashi RT. A opção profissional do aluno de enfermagem: um estudo na Escola de Enfermagem da USP. Nursing: Revista Técnica de Enfermagem, São Paulo 2001 maio;4(36):30-4.

15. Góes FOS. Evasão no Curso de Enfermagem da UFS [monografia de conclusão de Curso de Bacharel em Enfermagem]. Aracaju (SE): Departamento de Enfermagem e Nutrição, Universidade Federal de Sergipe; 1997. $36 \mathrm{f}$.

16. Padilha MICS, Nazário NO, Moreira MC. A compreensão do ideário da enfermagem para a transformação da prática profissional. Revista Brasileira de Enfermagem, Brasília (DF) 1997 jul/set;50(3):307-22.

Data de Recebimento: 12/07/2002

Data de Aprovação: 20/03/2004 